\title{
Ocular Morbidity among Orphanages
}

\author{
Shrestha MK, ${ }^{1}$ Wolf L, ${ }^{2}$ Shrestha U, ${ }^{2}$ Gurung K, ${ }^{1}$ Chansi BS, ${ }^{1}$ Dhungana P, ${ }^{1}$ Gurung R, ${ }^{1}$ Ruit S \\ 'Tilganga Eye Centre, Kathmandu, Nepal, ${ }^{2}$ University of California, San Francisco, San Francisco, CA, USA.
}

\section{ABSTRACT}

Introduction: The study assesses the spectrum of ocular morbidity and predictors of morbidity in children living in orphanages in the Kathmandu Valley.

Methods: A descriptive, cross-sectional survey was performed at 12 orphanages over a period of three months. The survey included a questionnaire and a complete eye examination, which included measurement of refraction, ocular deviation, and a fundus exam. Prevalence of ocular morbidity was calculated. Factors associated with ocular morbidity were examined using logistic regression.

Results: A total of 660 children were included in the study (median age nine years [range 0.25-15]; $53 \%$ male). The prevalence of ocular morbidity was $17.9 \%$ (118). Of those with ocular morbidity, $88.1 \%$ (104) had similar ocular problems bilaterally. The most common type of morbidity was refractive error, found in $70.3 \%$ (83) of those with ocular morbidity (12.6\% overall).

Conclusions: Refractive errors, which are largely correctable, are the greatest source of morbidity. In order to reduce childhood blindness, children living in orphanages are an appropriate group to target for future ocular screening in Nepal.

Key Words: children, Nepal, ocular morbidity, ocular screening, orphanage

\section{INTRODUCTION}

The prevalence of ocular morbidity in different groups of school children and populations has been published before in Nepal ${ }^{1-6}$ and other countries as well.
Orphans comprise a special population, which has been shown to exhibit growth and developmental delays, as well as other medical problems. In 2005, UNICEF estimated that there were 970,000 orphaned children

Correspondence:

Mr. Mohan Krishna Shrestha

Tilganga Eye Centre

Gaushala Bagmati Bridge, Kathmandu, Nepal.

E-mail: research@tilganga.com.np

Phone: 4493775 
living in Nepal. We have found high ocular morbidity patients presenting at Tilganga Eye Centre from local orphanages. This highlights a cause for concern among this population.

One of the priorities of Vision 2020 is childhood blindness. In order to better understand ocular health in orphaned children, the Tilganga Eye Center began an orphan ocular screening project in 2008 . This study aims to describe the prevalence of ocular morbidity and assess some of the risk factors amongst orphans based in the Kathmandu Valley.

\section{METHODS}

This is a cross sectional descriptive study conducted in twelve orphanages in the Kathmandu and Lalitpur districts in between March and May 2008. Children below 16 years of age were selected. Their eyes were thoroughly examined by a medical team of an optometrist and an ophthalmic assistant. The examination included measurement of refraction and visual acuity, convergence, accommodation test, fundoscopy and cover test. Children with oblique astigmatism, high phoria, any squint, or any ocular pathology were referred for further investigation and management.

Approval for the study was granted by the Tilganga Eye Centre Institutional Review Committee with verbal consent provided by all children's legal guardians. The primary outcome for this study was presence of ocular morbidity. Morbidities were divided into 12 discrete categories: amblyopia (including form deprivation, refractive, strabismic, and combined aniso-strabismus), conjunctivitis (including allergic and vernal keratoconjunctivitis), corneal opacity, Duane's retraction syndrome, glaucoma, eyelid morbidity (including blepharitis, chalazion, ptosis, and stye), maculopathy, ocular allergy, refractive errors (including myopia, hypermetropia, and astigmatism), retinopathy, strabismus (including phoria, tropia, and pseudostabismus), and others (including conjunctival cyst, dry eye, and epicanthus). Ocular morbidity was further defined as either bilateral (morbidity in both eyes) or unilateral (morbidity in one eye). The case of different morbidities in the right and left eyes was defined as "mixed" bilateral morbidity.

SPSS 11.5 was used for statistical analysis and Pearson's chi-square tests and logistic regression models were used. Two-sided p-values less than 0.05 were considered significant.

\section{RESULTS}

A total of 660 children were included. The median age was nine (mean 9.3), and ranged from three months to 15 years. Fifty-three percent of children were male. There were four religious groups reported, with $72 \%$ Hindu, 18\% Buddhist, 9\% Christian, and 1\% Muslim (Table 1).

Table 1. Demographic data on a population of children living in orphanages screened for ocular morbidity

\begin{tabular}{ll}
\hline Variable & Number of persons (\%) \\
\hline Sex & $352(53)$ \\
Male & $308(47)$ \\
Female & \\
Age group (years) & $116(18)$ \\
$0-5$ & $281(43)$ \\
$6-10$ & $263(40)$ \\
$11-15$ & \\
Religion & $116(18)$ \\
Buddhist & $61(9)$ \\
Christian & $475(72)$ \\
Hindu & $8(1)$ \\
Muslim &
\end{tabular}

Current ocular complaints were reported in $11.2 \%$ of children, and included blurred distance visual acuity $(42$, $6.4 \%)$, burning sensation $(7,1.1 \%)$, watering $(7,1.1 \%)$, ocular pain $(4,0.6 \%)$, headache $(4,0.6 \%)$, and others $(10,1.5 \%)$. Fourteen percent (90) of children reported some sort of past ocular history, which included an eye examination $(68,10.3 \%)$, and use of glasses $(22,3.3 \%)$.

The prevalence of ocular morbidity was $17.9 \%(118)$; among those, there was bilateral morbidity in 104 (88.1\%) and unilateral morbidity in $14(11.9 \%)$ children. No ocular morbidity was found in $82.1 \%$ (542) of children. Overall, the most common morbidity was refractive error, found in 83 children $(12.6 \%)$, comprising $70.3 \%$ of morbidity. The next most common morbidities were amblyopia and eyelid morbidity with $7(1.1 \%)$ and 5 $(0.8 \%)$ children, respectively. Conjunctivitis, corneal opacity, and strabismus were each found in $4(0.6 \%)$ children (Table 2). The most common bilateral morbidity was refractive error $(81,12.3 \%)$. One child $(0.2 \%)$ had "mixed" bilateral morbidity. The most common unilateral ocular morbidities were corneal opacity $(4,0.6 \%)$ and amblyopia (3, 0.5\%).

\section{\begin{tabular}{l|l|l|l|l|l|l|l|} 
JNMA & VILL 49 & Na. 1 & ISSUE & 177 & JAN-MAR, 201
\end{tabular}}


Table 2. Distribution of ocular morbidity in a population of children living in orphanages

\begin{tabular}{ll}
\hline Ocular morbidity & Number of persons (\%) \\
\hline None (normal eyes) & $542(82.1)$ \\
Refractive error & $83(12.6)$ \\
Amblyopia & $7(1.1)$ \\
Eyelid morbidity & $5(0.8)$ \\
Conjunctivitis & $4(0.6)$ \\
Corneal opacity & $4(0.6)$ \\
Strabismus* & $4(0.6)$ \\
Retinopathy & $3(0.5)$ \\
Ocular allergy & $2(0.3)$ \\
Duane's retraction syndrome & $1(0.2)$ \\
Glaucoma & $1(0.2)$ \\
Maculopathy & $1(0.2)$ \\
Others & $3(0.5)$ \\
\hline
\end{tabular}

*One patient had different morbidities in the right and left eyes consisting of dry eye and strabismus, and was included in the "Strabismus" group here.

Younger children were less likely to have any ocular morbidity, with those aged below five years and six to ten years being $68 \%$ and $59 \%$ less likely than those aged 11 to 15 years to have ocular morbidity. Children reporting Hindu religion were nearly twice as likely $(\mathrm{OR}=1.88)$ to have ocular morbidity than those reporting Buddhist, Christian, or Muslim religion. A history of use of glasses was strongly associated with ocular morbidity $(O R=18.21)$. Associations seen with female sex $(O R=1.51, p=0.063)$ and history of an eye examination $(O R=1.78, p=0.06)$ were not significant (Table 3$)$.

\section{DISCUSSION}

This study found a $17.9 \%$ prevalence of ocular morbidity in children living in orphanages in the Kathmandu Valley. The largest source of morbidity was refractive errors, found in $70.3 \%$ of children with ocular morbidity and $12.6 \%$ of children in overall. The majority of children had bilateral ocular problems.

Ocular screening studies in children have been performed in several different settings. In Nepal, the prevalence of ocular morbidity has been reported ranging from $11 \%$ in children attending government schools, 34\% in children attending private schools, to over half of 134 children in a sample of mentally retarded students in the Kathmandu Valley. ${ }^{2-4}$ This study found a moderate level of ocular morbidity in comparison to the previous Nepalese studies. In a study in primary school children in rural Tanzania, $10.2 \%$ of children had abnormalities or poor eyesight in at least one eye. ${ }^{11}$ A different study of secondary school students in Tanzania found $5 \%$ with bilateral poor eyesight and $2 \%$ with unilateral poor eyesight. ${ }^{12}$ A study in school children in Malaysia found presenting visual impairment in $10.1 \%$ of children. ${ }^{7}$ Similarly, in China, rates of presenting visual impairment were $10.3 \%$ in an urban setting and $16.6 \%$ in a rural setting..$^{8.9}$ In Australia, a study found that $5 \%$ of children had visual impairment in the worse eye. ${ }^{10}$ The prevalence of ocular morbidity reported from screening studies in other countries has been lower than this study, though they still advocated for national ocular screening programs. ${ }^{4,8,12-5}$ The results of this study indicate that the majority of ocular morbidity is related to correctable refractive errors

Table 3. Predictors of ocular morbidity in a population of children living in orphanages

\begin{tabular}{|c|c|c|c|c|}
\hline Variable & Total, & Any ocular morbidity, & Crude & Adjusted \\
\hline & $\mathbf{n}$ & n (\%) & Odds ratio $(95 \% \mathrm{CI})$ & Odds ratio $(95 \% \mathrm{CI}) *$ \\
\hline Total & 660 & $118(17.9)$ & --- & --- \\
\hline \multicolumn{5}{|l|}{ Sex } \\
\hline Female & 308 & $68(22)$ & $1.71(1.14-2.56)$ & $1.51(0.98-2.33)$ \\
\hline Male & 352 & $50(14)$ & 1.00 & 1.00 \\
\hline \multicolumn{5}{|l|}{ Age group (years) } \\
\hline $0-5$ & 116 & $10(9)$ & $0.24(0.12-0.48)$ & $0.32(0.16-0.66)$ \\
\hline $6-10$ & 281 & $33(12)$ & $0.33(0.21-0.52)$ & $0.41(0.26-0.67)$ \\
\hline $11-15$ & 263 & 75 (29) & 1.00 & 1.00 \\
\hline \multicolumn{5}{|l|}{ Religion } \\
\hline Hindu & 475 & $96(20)$ & $1.88(1.14-3.09)$ & $1.88(1.10-3.22)$ \\
\hline Other & 85 & $22(12)$ & 1.00 & 1.00 \\
\hline \multicolumn{5}{|l|}{ Past ocular history } \\
\hline Eye examination & 68 & $18(27)$ & $2.14(1.19-3.86)$ & $1.78(0.98-3.26)$ \\
\hline Use of glasses & 22 & $18(82)$ & $26.78(8.84-81.13)$ & $18.21(5.84-56.78)$ \\
\hline None & 570 & $82(14)$ & 1.00 & 1.00 \\
\hline
\end{tabular}

*Adjusted odds ratios are adjusted for all other variables shown in the table. 
Predictive factors for the outcome of all ocular morbidities have not been previously reported; however, predictive factors for refractive errors have been discussed in several studies. The arm of the Refractive Error Study in Children conducted in Nepal found associations between female sex and increased risk of hyperopia, and older age and increased risk of myopia. ${ }^{6}$ In the China arm of the study, female sex was associated with increased risk of both myopia and hyperopia, and risk of myopia increased with increased age while risk of hyperopia decreased with increased age. ${ }^{16}$ Similar associations were found in the arm conducted in Chile. ${ }^{17}$ In Tanzania, female sex was associated with increased risk of myopia, as was age 11 to 13 years (compared to 14 to 16 years and older than 17 years). ${ }^{12}$ While individual refractive errors were not distinguished in the current study, it is possible that these trends are consistent with the trend of increased risk of ocular morbidity with older age in the current study. The current study also found an association between past history of glasses use and increased ocular morbidity, which may be explained by the fact that these children had already been diagnosed with refractive errors. Further study is warranted to examine predictors of specific refractive errors in children living in orphanages in Nepal.

The current study has several limitations. First, this program was designed to provide a clinical service; therefore, the choice of orphanages was not randomized at the time of selection. However, the screening will eventually be offered to all orphanages in the Kathmandu valley. Second, information on ethnic group was not available for 58 of the children, who were taken in from the street without any family information. For this reason, we were not able to test for associations within ethnic groups. Finally, the children screened were all from orphanages in an urban area - the results may differ in children living in orphanages in rural areas, or in different urban areas. This sample from Nepal may not be generalizable to children living in orphanages in other settings. While true, this study does have the potential to inform health care policy on ocular screening in children in Nepal.

\section{CONCLUSIONS}

This study showed that largely correctable refractive errors are the greatest source of morbidity. Older age, Hindu religion and history of glasses use were identified as risk factors of ocular morbidity in orphans. Since orphaned children have not historically received ocular screening as other school-aged children do, they will be an important group to target for future programs.

\section{ACKNOWLEDGMENTS}

The authors gratefully acknowledge Bal Bahadur Chhetri, Bhoj Raj Gautam, and Tej Bikram Karki for history taking and examination, and Dr. Jyoti Devkota for advice on the statistical analysis.

\section{REFERENCES}

1. Sapkota YD, Adhikari BN, Pokharel GP, Poudyal BK, Ellwein LB. The prevalence of visual impairment in school children of upper-middle socioeconomic status in Kathmandu. Ophthalmic Epidemiol. 2008 Jan-Feb;15(1):17-23.

2. Ghising R, Shakya S, Rizyal A, Shrestha R, Shrestha S, WangHarris S. Prevalence of refractive error in mentally retarded students of Kathmandu Valley. Nepal Med Coll J. 2007 Dec;9(4):262-5.

3. Shrestha RK, Joshi MR, Ghising R, Pradhan P, Shakya S, Rizyal A. Ocular morbidity among children studying in private schools of Kathmandu valley: a prospective cross sectional study. Nepal Med Coll J. 2006 Mar;8(1):43-6.

4. Nepal BP, Koirala S, Adhikary S, Sharma AK. Ocular morbidity in schoolchildren in Kathmandu. Br J Ophthalmol. 2003 May;87(5):531-4.

5. Negrel AD, Maul E, Pokharel GP, Zhao J, Ellwein LB. Refractive error study in children: sampling and measurement methods for a multi-country survey. Am J Ophthalmol. 2000 Apr;129(4):421-6.

6. Pokharel GP, Negrel AD, Munoz SR, Ellwein LB. Refractive error study in children: results from Mechi Zone, Nepal. Am J Ophthalmol. 2000 Apr;129(4):436-44.

7. Goh PP, Abqariyah Y, Pokharel GP, Ellwein LB. Refractive error and visual impairment in school-age children in Gombak District, Malaysia. Ophthalmology. 2005 Apr;112(4):678-85.

8. He M, Huang W, Zheng Y, Huang L, Ellwein LB. Refractive error and visual impairment in school children in rural southern China. Ophthalmology. 2007 Feb;114(2):374-82.

9. He M, Zeng J, Liu Y, Xu J, Pokharel GP, Ellwein LB. Refractive error and visual impairment in urban children in southern China. Invest Ophthalmol Vis Sci. 2004 Mar;45(3):793-9.

10. Robaei D, Huynh SC, Kifley A, Mitchell P. Correctable and non-correctable visual impairment in a population-based sample of 12-year-old Australian children. Am J Ophthalmol. 2006 Jul;142(1):112-8.

11. Wedner SH, Ross DA, Balira R, Kaji L, Foster A. Prevalence of eye diseases in primary school children in a rural area of Tanzania. Br J Ophthalmol. 2000 Nov;84(11):1291-7.

12. Wedner SH, Ross DA, Todd J, Anemona A, Balira R, Foster A. Myopia in secondary school students in Mwanza City, Tanzania: the need for a national screening programme. Br J Ophthalmol. 2002 Nov;86(11):1200-6.

13. Miller LC, Chan W, Litvinova A, Rubin A, Tirella L, Cermak S. Medical diagnoses and growth of children residing in Russian orphanages. Acta Paediatr. 2007 Dec;96(12):1765-9.

14. He Z, Ji C. Nutritional status, psychological well-being and the quality of life of AIDS orphans in rural Henan Province, China. Trop Med Int Health. 2007 Oct;12(10):1180-90.

15. UNICEF. Nepal statistics: children (aged 0-17), orphaned due to all causes [Online]. 2005 [cited 2008 Jul 29]; [1 screen]. Available from: http://www.unicef.org/infobycountry/ nepal_nepal_statistics.html

16. Zhao J, Pan X, Sui R, Munoz SR, Sperduto RD, Ellwein LB. Refractive Error Study in Children: results from Shunyi District, China. American journal of ophthalmology. 2000 Apr;129(4):427-35.

17. Maul E, Barroso S, Munoz SR, Sperduto RD, Ellwein LB. Refractive error study in children: results from La Florida, Chile. Am J Ophthalmol. 2000 Apr;129(4):445-54.

\section{\begin{tabular}{l|l|l|l|l|l|} 
JNMA & VIL 49 & Na. 1 & ISSUE & 177 & JAN-MAR, 2010
\end{tabular}}

